GA-A24490

\title{
LAUNCHER PERFORMANCE AND THERMAL CAPABILITY OF THE DIII-D ECH SYSTEM
}

\author{
K. KAJIWARA, J. LOHR, I.A. GORELOV, M.T. GREEN, D. PONCE, \\ R.W. CALLIS, and R.A. ELLIS
}




\section{DISCLAIMER}

This report was prepared as an account of work sponsored by an agency of the United States Government. Neither the United States Government nor any agency thereof, nor any of their employees, makes any warranty, express or implied, or assumes any legal liability or responsibility for the accuracy, completeness, or usefulness of any information, apparatus, product, or process disclosed, or represents that its use would not infringe privately owned rights. Reference herein to any specific commercial product, process, or service by trade name, trademark, manufacturer, or otherwise, does not necessarily constitute or imply its endorsement, recommendation, or favoring by the United States Government or any agency thereof. The views and opinions of authors expressed herein do not necessarily state or reflect those of the United States Government or any agency thereof. 


\title{
LAUNCHER PERFORMANCE AND THERMAL CAPABILITY OF THE DIII-D ECH SYSTEM
}

by
K. KAJIWARA,
R.W. JOHR, I.A. GORELOV, M.T. GREEN, D. PONCE,
R.W. and R.A. ELLIS ${ }^{\prime}$

*Oak Ridge Institute of Science Education tPrinceton Plasmas Physics Laboratory

This is a preprint of a paper presented at the 20th IEEE/NPSS Symposium on Fusion Engineering, San Diego, California, October 14-17, 2003 and to be published in Fusion Science and Technology.

\author{
Work supported by \\ the U.S. Department of Energy \\ under Contract Nos. DE-AC03-99ER54463, \\ DE-AC02-76CH03073, and DE-AC05-760R00033
}

GENERAL ATOMICS PROJECT 30033

MARCH 2004 


\title{
Launcher Performance and Thermal Capability of the DIII-D ECH System
}

\author{
K. Kajiwara, ${ }^{1}$ J. Lohr, ${ }^{2}$ I.A.Gorelov, ${ }^{2}$ M.T. Green, ${ }^{2}$ D.Ponce, ${ }^{2}$ R.W.Callis, ${ }^{2}$ and R.A. Ellis ${ }^{3}$ \\ IOak Ridge Institute for Science Education, Oak Ridge, Tennessee \\ ${ }^{2}$ General Atomics, P.O. Box 85608, San Diego, California 92186-5608 \\ 3 Princeton Plasma Physics Laboratory, P.O. Box 451, Princeton, New Jersey 08543-0451
}

\begin{abstract}
The temperatures of components of DIII-D ECH launchers were observed during 2003 tokamak operation. The injected power was typically $500-700 \mathrm{~kW}$ and the pulse length was typically $2 \mathrm{~s}$. Plasma shots were performed at intervals of about 17 min from 9 a.m. to 5 p.m. The temperatures of a movable mirror, a fixed mirror and a launcher reached an equilibrium after about six hours of repetitive pulsing. The saturation temperature depends to some extent on the plasma stored energy. However, even in high $\beta$ plasma, the temperatures plateaued at acceptable values.
\end{abstract}

\section{INTRODUCTION}

A $110 \mathrm{GHz}$ electron cyclotron heating $(\mathrm{ECH})$ and current drive system has been developed on the DIII-D tokamak since 1997. The high power (up to $1 \mathrm{MW} /$ gyrotron) and long pulse (up to $10 \mathrm{~s}$ ) $\mathrm{rf}$ is generated by gyrotrons and delivered by wave guides connected to launchers in the tokamak vacuum vessel. The launchers are designed for radiative cooling for simplicity and to avoid potential water leakage inside the tokamak vacuum vessel. This design requires that the temperatures of launcher components be monitored to prevent the melting of the $\mathrm{rf}$ reflecting surfaces of the mirrors. The surface temperature could be increased abnormally by surface arcing, plasma disruption or radiation from the plasma. In this paper, the thermal performance of mirrors and wave guides during the 2003 DIII-D campaign is discussed.

The ECH system [1] consists of six $110 \mathrm{GHz}$ gyrotrons and three launchers which include two waveguides each (Fig. 1). Three of the gyrotrons were manufactured by Communications and Power Industries (CPI) [2] and the others were made by Gycom [3]. The CPI gyrotrons have chemical vapor deposition (CVD) diamond output windows which support $1 \mathrm{MW}, 10 \mathrm{~s}$ operation for Gaussian output if beams [4]. The Gycom gyrotrons have boron nitride windows, which limit the pulse lengths for these tubes to $2 \mathrm{~s}$ with $750 \mathrm{~kW}$ rf generation. The $\mathrm{rf}$ is transported by $\sim 100 \mathrm{~m}$ of $31.75 \mathrm{~mm}$ diameter evacuated corrugated waveguide carrying the $\mathrm{HE}_{1,1}$ mode. Each wave guide has a pair of grooved polarizers which can produce arbitrary elliptical polarization of the wave.

\section{ECH LAUNCHERS}

The DIII-D ECH system uses three launcher assemblies, each of which can inject rf power from two gyrotrons. Poloidal and toroidal steering is provided using movable mirrors of different designs to direct the rf beams. Eddy current induced forces arising during disruptions are a concern for the actuator assemblies on the movable mirrors, which have limited ability to react the forces. Therefore, mirror designs which minimize the volume of high conductivity copper while maintaining low resistivity reflecting surfaces have been developed. The mirrors are radiatively cooled, leading to a requirement to evaluate the thermal performance of the three different mirror designs for the expected maximum if energy, $800 \mathrm{~kW}, 10 \mathrm{~s}$.

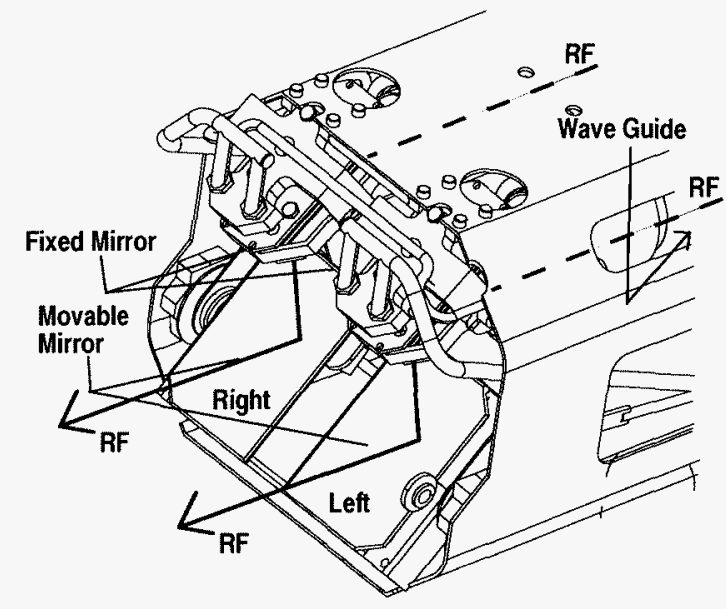

Fig. 1. Launcher assembly. Each launcher has two wave guides. The RTDs are located on the back surfaces of the fixed mirrors and movable mirrors. The waveguide temperature is also observed near the launching end.

One mirror, the "GA mirror" is made from Glidcop, with a thick center, providing thermal inertia, and thin periphery, reducing disruption forces. This mirror is grooved and blackened on the back to increase radiative cooling. This mirror design and simulation analysis, using the finite element code COSMOS [5], is reported in Ref. [6]. For this mirror, the experimental temperature increase was in good agreement with the simulation [7].

A second mirror is made of graphite with a molybdenum reflecting surface brazed to it [Fig. 2(a)]. This design, designated "PPPL99" significantly reduces eddy currents and easily withstands the disruption forces. However, the surface temperature is higher than for the GA mirror because of the higher resistivity of molybdenum. Therefore, the pulse length is limited to $5 \mathrm{~s}$.

The third mirror design is called the "PPPL01" mirror, which has a sandwich structure of Glidcop and stainless steel [Fig. 2(b)]. The reflecting surface on this mirror is a thin Glidcop layer supported by the sandwich. This design has the best overall performance of the three and meets the power, pulse length and duty cycle requirements.

The launchers are monitored by a set of diagnostics. Each dual launcher has ten resistance temperature devices (RTDs), two Langmuir probes and two video camera ports. Four of the RTDs are attached to the back surfaces of the movable mirrors (two RTDs each mirror). The other four RTDs are mounted to the back surfaces of the fixed mirrors and one RTD is on each launcher waveguide. Fiberoptically coupled video is used to detect launcher arcing and this video is recorded for each launcher waveguide, providing redundant arc detection.

In the DIII-D 2003 campaign, the "PPPL99" and "PPPLO1" mirrors were used. 


\section{(a) PPPL99 mirror: Graphite}

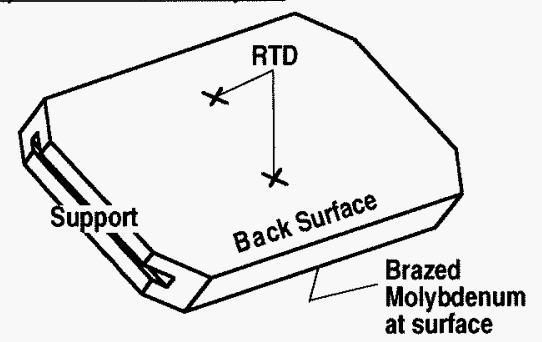

(b) PPPL01 mirror: Glidcop and Stainless

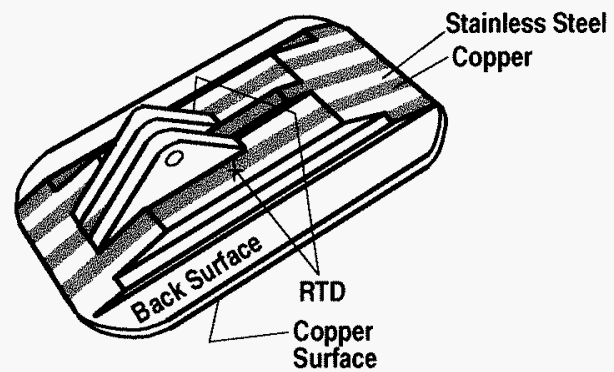

Fig. 2. Schematic view of the PPPL99 mirror and PPPL01 mirrors. The surface of the PPPL99 mirror is molybdenum and the PPPL01 is Glidcop. Both mirrors have two RTDs attached to their back surfaces.

\section{PRELIMINARY EXPERIMENT}

To check the RTD system, a simple experiment we performed on the test stand as described in Fig. 3. Additional RTDs were prepared at positions $\alpha, \beta$ and $\gamma$ indicated in the figure. RTD\#1 and RTD\#2 are the normally installed RTDs which remained in place following the tests. An ice cube was held against the mirror surface for $60 \mathrm{~s}$ with a thin plastic barrier sheet. The response of all the RTDs was then measured.

Fig. 4 shows the time evolutions of the responses of all the RTDs to the application of the ice cube. After about $400 \mathrm{~s}$, all the RTDs on the PPPL99 mirror with molybdenum/ graphite, have reached the same temperature. The response of the PPPL01 sandwich mirror is seen to be about twice as rapid. This indicates that the RTD system is working well.

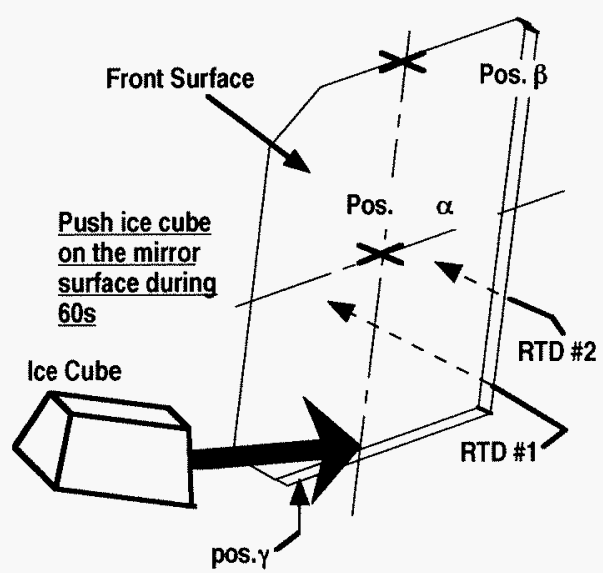

Fig. 3. Schematic view of RTD system check experiment. The ice was held against the surface for $60 \mathrm{~s}$ with a thin plastic protective barrier. Diagnostic RTDs were attached at the positions indicated by $\alpha, \beta$ and $\gamma$. RTD\# 1 and RTD\#2 are the regular RTDs which were used during the plasma experiments.
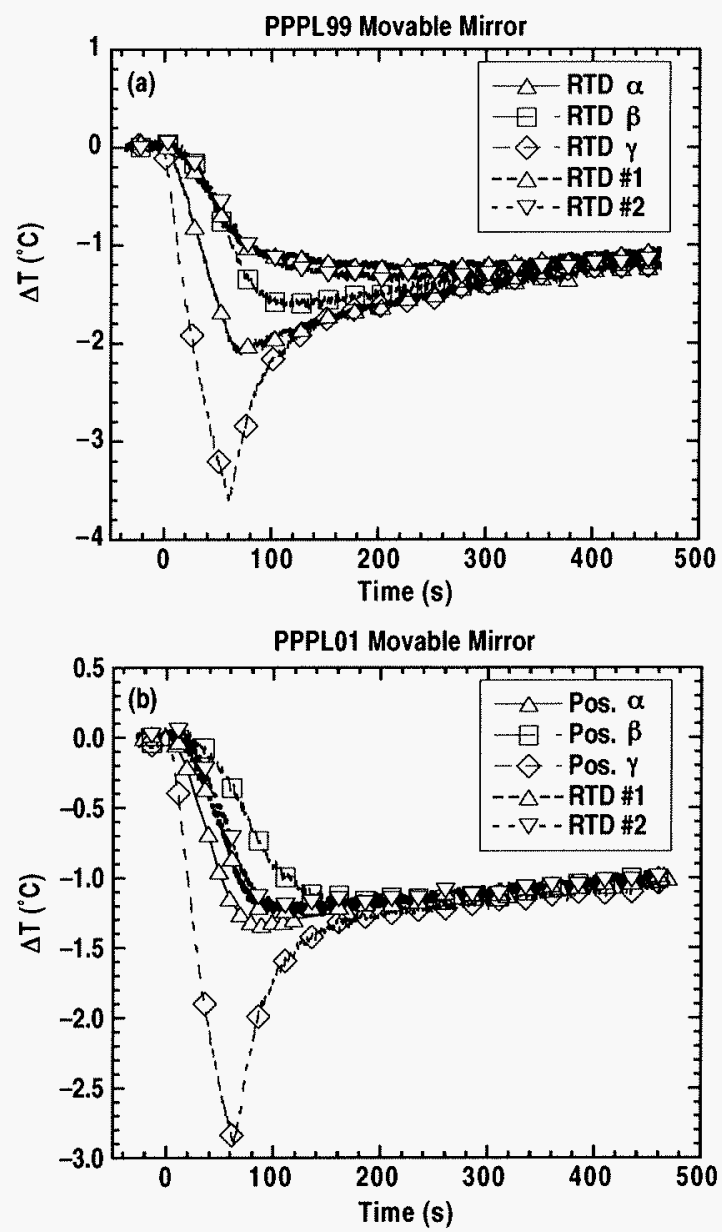

Fig. 4. The time evolution of the measured temperatures for the ice experiment for (a), the PPPL99 movable mirror and (b), the PPPL01 movable mirror.

During plasma operations the time interval between plasma shots is more than $10 \mathrm{~min}$. Therefore, for both designs, the entire mirror comes to one temperature between shots. The results show that $R T D \# 1$ and $\# 2$, which are located on the back surface, are useful for monitoring the base temperature increases of the mirror body, but will not accurately follow the surface temperatures for 6 second tokamak pulses.

\section{PLASMA EXPERIMENTS}

Fig. 5 shows the typical temperature increases for the PPPL99, the PPPL01, and one of the fixed Glidcop focusing mirrors on the PPPL01 launcher plus the launcher waveguides fed by the Gycom-2 gyrotron also on the PPPL01 launcher during one day of tokamak operation. All measured temperatures are about $30^{\circ} \mathrm{C}$ at the beginning of the plasma experiments. These temperatures are somewhat higher than the actual temperature because the temperatures are measured by two wire RTDs, which do not provide compensation for lead resistance. nevertheless, the relative temperature increases are accurate. The data were acquired every $200 \mathrm{~ms}$ for $10 \mathrm{~min}$ after the shot. In some cases, straight lines were used to connect the data for different shots. The time between plasma shots this day typically was about $17 \mathrm{~min}$ and the typical $\mathrm{rf}$ pulse lengths were $2 \mathrm{~s}$. therefore, the duty cycle was about $0.2 \%$. The power injected into the tokamak for the PPPL99 


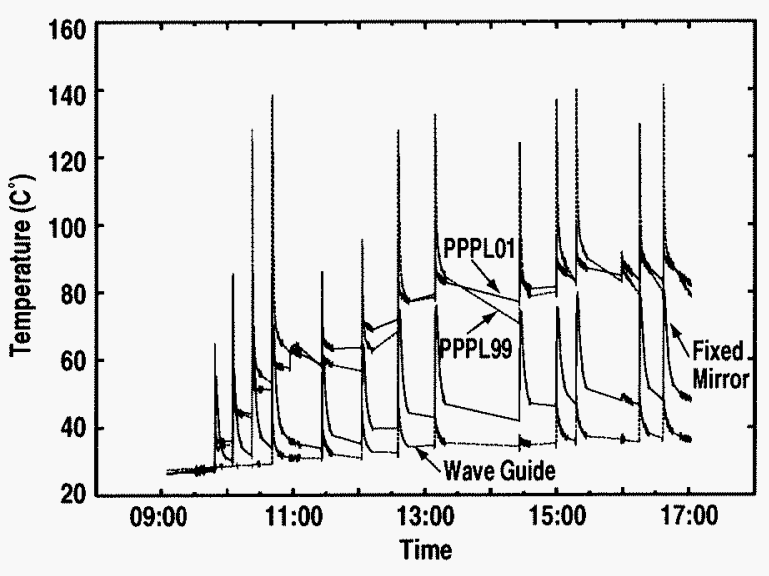

Fig. 5. Temperature increases of the PPPL99 movable mirror, PPPL01 movable mirror, fixed mirror and waveguide measured by two wire RTDs. Injected rf power for the PPPL99 and waveguide were about $700 \mathrm{~kW}$ and for the PPPL01 and fixed mirror about $500 \mathrm{~kW}$. The typical rf pulse length was $2 \mathrm{~s}$. The plasma shot interval was about $17 \mathrm{~min}$.

movable mirror was about $700 \mathrm{~kW}$ and for the PPPL01 movable and fixed mirrors was about $500 \mathrm{~kW}$. The waveguide power was about $700 \mathrm{~kW}$.

The spikes in the plots correspond to plasma shots with of injection. The heights of the spikes show the peak measured temperatures, which are lower than the peak mirror surface temperatures. Despite the time response issues addressed earlier, the peak temperature of the PPPL99 mirror with molybdenum surface was 2-3 times higher than the PPPL01 mirror with Glidcop surface. The surface temperature is caused by ohmic loss and is proportional to the electrical resistivity of the surface. The resistivity of molybdenum is $12.7 \mu \Omega$, which is 3.5 times higher than Glidcop. The temperature decrease of the PPPL99 mirror following the pulse is faster than PPPL01 mirror. The volume thermal capacity of graphite is about $1.6-2.2 \mathrm{JK}^{-1} \mathrm{~cm}^{-3}$, which is 1.6 2.2 times lower than Glidcop and stainless steel. Therefore, for the same energy applied to the mirror surfaces, the substrate temperature will be higher for the graphite than for the copper/stainless steel with concomitant 7-23 times higher radiative cooling rate, under the assumption of $\mathrm{T}^{4}$ dependence of the radiation.

The temperature increase of the fixed Glidcop mirror is lower than for either of the movable mirrors. Not only is the initial power deposition low for this mirror, but also there is substantial energy conduction to its supports compared with the movable mirrors, which are primarily cooled by radiation. The waveguide temperature was practically not increased during the pulse, showing that there was no extraordinary if heating at the end of the waveguide.

The long term temperature increase plateaued after about $6 \mathrm{~h}$ of operation at a measured temperature about $50^{\circ} \mathrm{C}$ higher than the starting temperature for both the PPPL99 and PPPL01 mirrors, well within the values required to avoid mirror surface damage. The fixed mirror and waveguide had even smaller temperature increases than the movable mirrors. Under normal operation, temperature ratcheting is not a concern for either mirror design.

In addition to the rf induced heating of the mirrors, radiation from the plasma also heats the mirrors and surrounding structure. This is examined in Fig. 6. For the PPPL01 movable mirror. The plateau temperature in the high $\beta$ plasma case with higer $P_{\text {inj }}$ and $P_{r a d},\left(\beta_{N} \sim 3-4\right)$ was about $60^{\circ} \mathrm{C}$, which was $30^{\circ} \mathrm{C}$ higher than the low beta case $\left(\beta_{\mathrm{N}} \sim 1-\right.$ 2 ). The high $\beta$ case was for one of the highest $\beta$ operational days for DIII-D and included several plasma disruption shots. Nevertheless, the temperature at the end of the day was well within acceptable limits.

For normal DIII-D shots, about $40 \%$ of the mirror temperature increase is not related to ECH injection at all, but arises from heating of the launcher and surroundings by plasma radiation. This is indicated in Fig. 7, in which $500 \mathrm{~kW}$ injection at 1.0-1.5 s pulse length is compared with no rf injection for the same series of plasma shots. The plasma normalized $\beta$ was about 1 . The equilibrium increases of launcher mirror temperatures with and without $\mathrm{ECH}$ were $35^{\circ} \mathrm{C}$ and $15^{\circ} \mathrm{C}$ respectively.

By calculating the energy delivered to the mirrors by the $\mathrm{ECH}$, the energy input from the plasma can be estimated. The input energy of $\mathrm{ECH}$ is $500 \mathrm{~kW} \times 0.002 \times 1 \mathrm{~s} / 115 \mathrm{~cm}^{2}=$ $8.7 \mathrm{~J} / \mathrm{cm}^{2}$. Here, the factor 0.002 is the rf absorption of the mirror surface and $115 \mathrm{~cm}^{2}$ is the surface area of the PPPL01 movable mirror. Therefore, the injected energy from the plasma is roughly calculated as $8.7 \mathrm{~J} / \mathrm{cm}^{2} \times 15^{\circ} \mathrm{C} / 20^{\circ} \mathrm{C}=$ $6.5 \mathrm{~J} / \mathrm{cm}^{2}$. The plasma auxilary heating energy was approximately $5 \mathrm{MJ}$ for NBI and $3.6 \mathrm{MJ}$ for ECH for these DIII-D shots. Therefore, the energy input to the mirror surface was $1.0 \mathrm{~J} / \mathrm{cm}^{2} / \mathrm{MJ}$ of energy input to the plasma. This is of the same order as found in the previous study $\left(0.36 \mathrm{~J} / \mathrm{cm}^{2}[6]\right)$.

\section{CONCLUSION}

The temperatures of DIII-D ECH launcher components were observed during 2003 tokamak operation. The temperature was monitored through a whole day (typical plasma shot interval $17 \mathrm{~min}$, rf power was $500 \mathrm{~kW}$ for PPPL01 and $700 \mathrm{~kW}$ for PPPL99, pulse length of rf was $2 \mathrm{~s}$ ). All the temperatures have plateaued by about 15:00. The temperatures of two types of movable mirror (PPPL99 and PPPL01) were increased by about $50^{\circ} \mathrm{C}$ above the beginning of the plasma operation. This was a small temperature increase from the view point of the avoidance of the melting of the mirror surface.

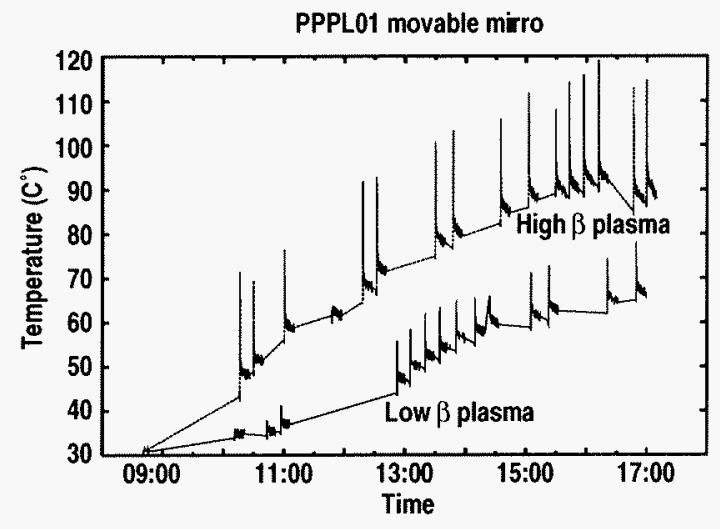

Fig. 6. Temperature increase of PPPL01 movable mirror for low $\beta$ plasma $\left(\beta_{N^{\sim}}\right.$ 1-2) operation and high $\beta$ plasma $\left(\beta_{N^{\sim}}\right.$ $3-4)$ operation. The if power was about $500 \mathrm{~kW}$ and typical pulse length was $2 \mathrm{~s}$. 


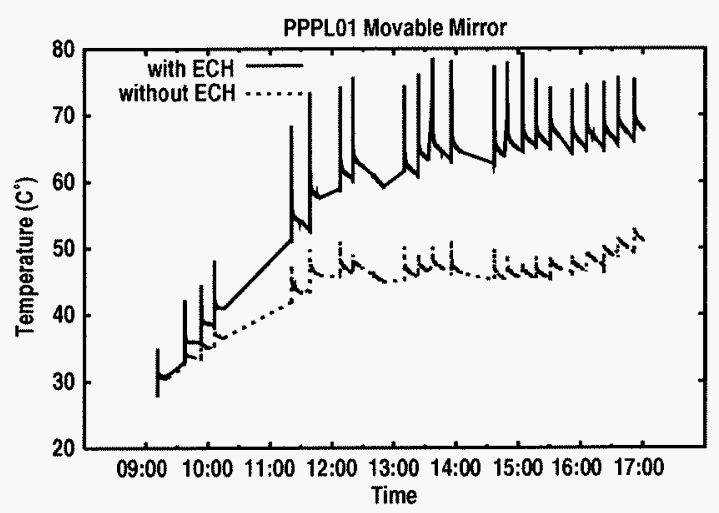

Fig. 7. Temperature increase of the PPPL01 mirror compared without ECH and with ECH. For the ECH case, the injected power is about $500 \mathrm{~kW}$ and the rf pulse length was typically $1-1.5 \mathrm{~s}$. Both cases were for the same plasma experiment.

A certain amount of mirror heating by plasma radiation was observed. However, the combination of $2 \mathrm{~s} \mathrm{ECH}$ and one of the highest $\beta$ operational days only resulted in a $60^{\circ} \mathrm{C}$ temperature increase. This was not a problematic temperature increase. The roughly estimated energy input from plasma to the movable mirror surface is $1.01 \mathrm{~J} / \mathrm{cm}^{2} / \mathrm{MJ}$ of energy input to plasma.

\section{ACKNOWLEDGMENT}

Work supported by the U.S.Department of Energy under Contracts DE-AC03-99ER54463, DE-AC02-76CH03073, and DE-AC05-76OR00033.

\section{REFERENCES}

[1] Lohr, J., et al., "High power long pulse performance of the DIII-D gyrotron installation," Proc. of 12th Joint Workshop on Electron Cyclotron Emission and Electron Cyclotron Resonance Heating, Aix-en-Provence, France (2002).

[2] Communications and Power Industries, Palo Alto CA USA

[3] Gycom, Nizhny Novgorod, Russia

[4] Gorelov, Y.A., et al., "Characteristics of diamond windows on the $1 \mathrm{MW}, 110 \mathrm{GHz}$ gyrotron systems on the DIII-D tokamak," Proc. of 27th Int. Conf. on Infrared and Millimeter waves, San Diego, California (2002).

[5] COSMOS, A Finite Element Analysis Code, Structural Research, Santa Monica, California, USA.

[6] Baxi, C.B. et al.,"Thermal design of GA ECH launcher mirror for long pulse operation," Proc. of 19th IEEE/NPSS Symp. on Fusion Engineering, Atlantic City, New Jersey (2002).

[7] Kajiwara, K., et al., "Launcher performance in the DIII-D ECH system," Proc. of 15th Topical Conference on Radio Frequency Power in Plasmas, Moran, Wyoming (2003). 